Printed Version: (ISSN 2090-5262)

Online Version: (ISSN 2090-5270)

November 2013, Volume 3, No. 3 Pages (87 - 93)

\title{
Effect of Physical Training on Lymphatic System, Cell Function and Physical Fitness
}

\author{
Maha Khalil Mohamed*, Ayat Yehia Abd Elhamid Bagato**, Manal Ahmed Mohamed***
}

\begin{abstract}
Exercise produce waste products induce muscle atrophy and may lead to fatigue. Blood and lymphatic vessels together form the circulatory system, allowing the passage of fluids and molecules within the body. The formed waste products and ions are transported via initial lymphatic capillaries to collecting vessels, to lymph nodes, and finally back to the blood. Ions accumulations lead to depolarization of cell membranes causing cell dysfunction. Accordingly, we investigated the role of lymph in waste products and ions clearance in cell function integrity. Eight physically active, non athletic females from the physical rehabilitation unit in the National Heart Institute, Giza, volunteered to participate in physical program (1hr. daily)/3days/12 weeks. Blood was taken before and immediately following exercise tests before and after the program and analyzed for serum ions ( $\mathrm{Na} \& \mathrm{~K})$ using ion selective electrode. Lactate/pyruvate (La/P) ratio was assessed by using commercial photometric kits. There were no significant $(P<0.05)$ differences in ions levels either before and after training exercise or after compared to before program. La/P was highly maintained around optimum ratio after exercise after program in relation to before program. Regular training program increased lymph function and regulation of waste product clearance with improved cellular integrity.
\end{abstract}

Keywords: lymphatic system - lactate/pyruvate - cell function - exercise training.

\section{Introduction}

$\mathrm{P}$ hysical exercise is induced by muscle contractions which in turn affects lymph flow. The lymphatics in skeletal muscle consist entirely of lymphatic capillaries only with no smooth muscles (Skalak et al., 1984), and are thus unable to contract spontaneously. The lymphatics lie adjacent to arterioles, and are surrounded by muscle fibers, to both of which the lymphatic endothelial cells are firmly connected by collagen fibers leading to unidirectional flow (Schmid-Schonbein, 1990).

The main function of large lymphatics is to transport fluids, macromolecules, and migrating

\footnotetext{
* Biological science and sports health department, faculty of physical education for girls, Helwan university, Egypt

** Lecturer in Biological science and sports health department, faculty of physical education for girls, Helwan university, Egypt *** Lecturer of biochemistry, National Heart Institute, Inbaba, Giza, Egypt.
}

inflammatory cells pass through the blood capillary endothelia, enter the tissues, and are subsequently absorbed into the lymphatic vessels back into the blood circulation (Quick et al., 2009). The fine lymphatic microvasculature is responsible for the drainage of the interstitial fluid components, regulating interstitial fluid pressure and cell trafficking. It is surprising that lymphatic endothelial cells have until recently been poorly characterized, at least from a molecular point of view (Pepper and Skobe 2003).

Blood flow in skeletal muscles increases markedly during exercise, and this exerciseinduced hyperemia results in increased net capillary filtration, increases electrolytes and waste products in the interstitial fluid and addresses the need for increased lymph flow to maintain optimal conditions in the muscle (Allen et al., 2008). The deviation from the plasma concentrations was largest for both electrolytes in fluid sampled with micropipettes, 
suggesting an excess of negative charges in tissue fluid relative to plasma (Haljamae et al., 1974).

During exercise the lactate and pyruvate released from muscles to blood may influence the intracellular $\mathrm{L} / \mathrm{P}$ of the brain and thereby provide a feedback signal that could increase tissue blood flow (Rasmussen et al., 2009). Putman et al. (2003) concluded that the traininginduced attenuation of the rise in plasma $\mathrm{H}$ during incremental exercise resulted from adaptive changes within muscles (less Lactate production and less water uptake) and erythrocytes (less uptake of Lactate, $\mathrm{Cl}$ and $\mathrm{K}$ ), leading to greater strong ion difference and lower total concentration of weak acids in both arterial and femoral venous plasma.

The aim of this study is to investigate the role of a hypothesized training program on lymphatic system efficacy in the control of electrolyte concentrations, fluid shifts, as well as physiological and biochemical events that occur within the muscular exercise. Ions accumulations lead to depolarization of cell membranes causing cell dysfunction (Juel et al., 2000). Accordingly, we investigated the role of lymph in waste products and ions clearance for keeping cell function integrity. We hypothesized that venous blood potassium, sodium and lactate/pyruvate $(\mathrm{La} / \mathrm{P})$ ratio before and after an exercise session can reveal the lymphatic circulation role in clearance of waste products before and after the hypothesized program.

\section{Material and Methods}

\section{Subjects:}

Eight physically active, non athletic females from the physical rehabilitation unit in the National Heart Institute, Giza, volunteered for physical training program. Procedures were explained to the subjects prior to them, signing a written, informed consent form for participation. None of the participants were smoker, taking medications or receiving supplements. There were no clinical or analytical evidence for any diseases.

\section{Program Design:}

Volunteers participated in a physical program (1hr. daily)/3days/12 weeks. Table (1) depicts the program sessions graded through three months.

(Table 1)

Program sessions graded through three months

\begin{tabular}{|c|c|c|c|c|c|}
\hline Month & \multicolumn{5}{|c|}{ SESSION } \\
\hline & Intensity & Warming up & RUN (on treadmill) & Weight exercises & Elasticity exercises \\
\hline 1st & $60 \%$ & $20 \mathrm{~min}$ & $15 \mathrm{~min}$ & $15 \mathrm{~min}$ & $10 \mathrm{~min}$ \\
\hline 2nd. & $70 \%$ & $20 \mathrm{~min}$ & $15 \mathrm{~min}$ & $15 \mathrm{~min}$ & $10 \mathrm{~min}$ \\
\hline 3rd. & $75 \%$ & $20 \mathrm{~min}$ & $15 \mathrm{~min}$ & $15 \mathrm{~min}$ & $10 \mathrm{~min}$ \\
\hline
\end{tabular}

\section{Physical determinants:}

Volunteers are subjected to physical exercises before and after the program, recorded results are compared. These exercise comprised a velocity exercise for $50 \mathrm{~m}$, endurance exercise for $600 \mathrm{~m}$ running, arm muscle power, leg muscle capacity, and elasticity and agility tests.

\section{Blood analysis:}

Blood samples were collected before and immediately after exercise test, in heparinized tubes, centrifuged at $1000-1500 \mathrm{~g}$ for $10 \mathrm{~min}$., plasma were separated and frozen at $-20{ }^{\circ} \mathrm{C}$ until analysis. Lactate and pyruvate were measured using a colouremetric assay kits. Plasma sodium $(\mathrm{Na}+)$ and Potassium $(\mathrm{K}+)$ were measured using ion selective electrode.

\section{Statistical analysis:}

A Computer program (SPSS version 15) was used to analyze obtained data. Data expressed as Student's Mean, standard deviation while Wilcoxon Sign Ranks Test were used to examine the difference between baseline and after exercise measurements before and after the proposed program. Probability was assigned significant at $<0.05$.

\section{Results}


Obtained data revealed no significant variations in the clinical or biochemical investigated parameters (Tables $2 \& 3$ ) at rest. The variables that maybe likely to affect the results of the research as (age- weight, height and training age) are presented in table (2) and all values of the skewness lies between $( \pm 3)$ which achieved the equivalence of the subjects.

Table (2)

Clinical Data for subjects volunteered for this study

\begin{tabular}{|c|c|c|c|c|c|}
\hline Variable & Unit & $\mathrm{M}$ & $\mathrm{S} . \mathrm{D}$ & $\mathrm{K}$ & $\mathrm{S}$ \\
\hline Age & Year & 21.9 & 2.26 & 0.321 & -0.085 \\
\hline Weight & $\mathrm{Kg}$ & 52.8 & 4.559 & -1.092 & -0.415 \\
\hline Height & $\mathrm{Cm}$ & 160.5 & 1.433 & -0.679 & -1.263 \\
\hline T. age & Year & 6.4 & 1.922 & 2.135 & 0.861 \\
\hline
\end{tabular}

\section{M=Mean S. D. = Standard deviation $K=$ Kurtosis $S=$ Skewness}

There were decreased blood lactate levels after increased pyruvate levels, lead to significant exercise after the program compared to that decrease in $\mathrm{La} / \mathrm{P}$ ratio $(\mathrm{P}<0.01)$ (Tables $3 \& 4)$. obtained before program with reverse results of

(Table 3)

Biochemical data for subjects participated in this study before and after program (Mean $\pm S$. D.)

\begin{tabular}{|c|c|c|c|c|}
\hline & \multicolumn{2}{|c|}{ Before Program } & \multicolumn{2}{c|}{ After Program } \\
\hline & Rest & After exercise & Rest & After exercise \\
\hline $\mathrm{Na}(\mathrm{mmol} / \mathrm{l})$ & $140.75 \pm 3.54$ & $140.62 \pm 2.56$ & $139.87 \pm 2.75$ & $140 \pm 2.51$ \\
\hline $\mathrm{K}(\mathrm{mmol} / \mathrm{l})$ & $4.11 \pm 0.2$ & $4.1 \pm 0.19$ & $4.08 \pm 0.24$ & $4.15 \pm 0.18$ \\
\hline $\mathrm{LAC}(\mathrm{mmol} / \mathrm{l})$ & $1.16 \pm 0.16$ & $4.91 \pm 0.62$ & $1.13 \pm 0.15$ & $4.24 \pm 0.39$ \\
\hline $\mathrm{PYRU}(\mu \mathrm{mol} / \mathrm{l})$ & $73.25 \pm 6.07$ & $166.5 \pm 14.45$ & $71.5 \pm 5.37$ & $222.5 \pm 20.56$ \\
\hline $\mathrm{La} / \mathrm{P}$ & $15.85 \pm 2.12$ & $27.64 \pm 2.65$ & $15.83 \pm 2.29$ & $20.09 \pm 2.37$ \\
\hline
\end{tabular}

$\mathrm{Na}=$ Sodium, $\mathrm{K}=$ Potassium, LAC $=$ Lactate, $\mathrm{PYRU}=$ Pyruvate, La $/ \mathrm{P}=$ Lactate $/$ pyruvate ratio

(Table 4)

Wilcoxon related paired sample for participants of this study at rest related to after exercise

\begin{tabular}{|c|c|c|c|c|}
\hline & \multicolumn{2}{|c|}{ Before Program } & \multicolumn{2}{c|}{ After Program } \\
\hline Rest \&After exercise & $\mathrm{Z}$ & $\mathrm{P}$ & $\mathrm{Z}$ & $\mathrm{P}$ \\
\hline Sodium $(\mathrm{Na})$ & 0.38 & 0.71 & 0.14 & 0.89 \\
\hline Potassium $(\mathrm{K})$ & 0.33 & 0.74 & -0.11 & 0.92 \\
\hline Lactate $(\mathrm{Lac})$ & -2.52 & 0.01 & -2.35 & 0.01 \\
\hline Pyruvat (P) & -2.52 & 0.01 & -2.53 & 0.01 \\
\hline La/P ratio & -2.52 & 0.01 & -2.38 & 0.01 \\
\hline
\end{tabular}

(Table 5)

Wilcoxon related paired sample for participants of this study at rest related to rest and after related to after (exercise) before and after the program

\begin{tabular}{|c|c|c|c|c|}
\hline & \multicolumn{2}{|c|}{ Rest \& Rest } & \multicolumn{2}{c|}{ After \& After (Exercise) } \\
\hline Before \& after (Program) & $\mathrm{Z}$ & $\mathrm{P}$ & $\mathrm{Z}$ & $\mathrm{P}$ \\
\hline Sodium (Na) & 0.14 & 0.89 & 0.38 & 0.71 \\
\hline Potassium (K) & -0.11 & 0.92 & -0.6 & 0.55 \\
\hline Lactate (Lac) & -0.35 & 0.73 & -2.68 & 0.01 \\
\hline Pyruvat (P) & -0.59 & 0.55 & -2.52 & 0.01 \\
\hline La/P ratio & -0.14 & 0.89 & -2.52 & 0.01 \\
\hline
\end{tabular}

Physical results revealed significant variation in obtained before program. Table (6) represents all exercises after program compared to that results of these physical parameters. 
(Table 6)

Wilcoxon related paired sample for physical parameters obtained in this study (Before program compared to after program)

\begin{tabular}{|c|c|c|c|c|}
\hline & Before & After & Z & P \\
\hline Velocity (50 m. (sec)) & $6.51 \pm 1.32$ & $6.42 \pm 1.12$ & 2.88 & 0.01 \\
\hline Endurance (600 m (min)) & $5.54 \pm 1.71$ & $4.94 \pm 1.18$ & 2.52 & 0.01 \\
\hline Arm muscle power (no.) & $6.52 \pm 1.62$ & $6.22 \pm 1.25$ & 2.38 & 0.02 \\
\hline Leg muscle capacity (cm) & $6.90 \pm 1.28$ & $6.97 \pm 1.32$ & 2.38 & 0.05 \\
\hline Elasticity (cm) & $6.15 \pm 1.35$ & $6.12 \pm 1.3$ & 2.52 & 0.01 \\
\hline Agility (sec) & $6.0 \pm 1.33$ & $6.12 \pm 1.67$ & 2.74 & 0.01 \\
\hline
\end{tabular}

\section{Discussion}

The present study was designed to investigate the effect of a training program on the skeletal muscle lymph flow dynamics during a prolonged period of time. We hypothesized that lymphatic flow increases with muscle contraction, propelling electrolytes through lymphatic ducts to main venous blood stream. This keeps cell wall $\mathrm{K} / \mathrm{Na}$ gradients about 0.1 volts, preserving cell function integrity. Repeated muscle contractions lead to $\mathrm{K}+-$ induced depolarization, reduces excitability during exercise with final cell fatigue (Karelis et al. 2004). Training program may lead to up regulation of cell integrity and improve $\mathrm{La} / \mathrm{P}$ ratio.

Our results revealed significant increase $(\mathrm{P}$ $<0.01$ ) in plasma lactate, pyruvate and $\mathrm{La} / \mathrm{P}$ ratio after the exercise irrespective to program. Neither $\mathrm{K}$ nor $\mathrm{Na}$ ions levels are changed due to exercise before or after the training program. After the program, plasma lactate levels were significantly decreased after the exercise compared to that before the program while pyruvate levels are increased with net decrease in $\mathrm{La} / \mathrm{P}$ ratio $(\mathrm{P}<0.01)$.

Previous study discussed that 5-20 min of heavy exercise leads to lowered intracellular $\mathrm{K}$, raised $\mathrm{Na}$ ions, which may double, and increased lactate. Interstitial $\mathrm{K}$ ions concentrations are double increased while $\mathrm{Na}$ is decreased with rather increase in lactate ions (Cairns and Lindinger, 2008). Rasmussen et al. (2009) found arterial pyruvate and lactate increased after 60 and $40 \mathrm{sec}$, respectively after exercise onset.

Haljamae et al. (1974) found very little difference in sodium, potassium, and chloride concentrations between the two "interstitial fluids" and plasma fluids at resting state. They observed that interstitial fluid samples after muscle contractions had lower concentration of chloride and higher sodium concentration than plasma. The deviation from the plasma concentrations were suggesting an excess of negative charges in tissue fluid in relative to plasma may due to increased lactate concentrations. This hypothesis was investigated by other studies (Clausen 2003, Kristensen et al., 2005 and McKenna et al., 2008). They found that muscle $\mathrm{K}, \mathrm{Na}$ and $\mathrm{Cl}$ disturbances and $\mathrm{Na}-\mathrm{K}$ pump inactivation under the effect of intensive or prolonged exercise can be considered the implications for fatigue.

Lindinger et al. (1995) suggested that exerciseinduced increase in plasma $\mathrm{K}$ and Lactate depends on the mass of contracting muscle, the trained state of the contracting muscles, and the fiber types of the active muscle groups. They also found rapid kinetic increase and decrease of plasma $\mathrm{K}$ with half life of $20-30 \mathrm{sec}$. but those for lactate is much slower up to $25 \mathrm{~min}$. Decherchi et al., (1998) found that modifications of afferent activities from tibialis anterior muscle in rat by tendon vibrations lead to increase of interstitial potassium or lactate concentration and cause electrically-induced fatigue.

At the onset of exercise, accumulation of intracellular osmolytes such as inorganic phosphate, creatine, and lactate lead to rapid osmotic movement of water from the vascular compartment into contracting tissues. This results in increase in the quantity of $\mathrm{K}$ present in plasma. Also, contracting muscle release $\mathrm{K}$, accounted for about $3 \%$ of the net amount of $\mathrm{K}$ released into plasma (Kristensen et al., 2006).

When a muscle contracts, the lymphatics dilated, allowing interstitial fluid to enter. Accordingly, when the muscle expands, the lymphatics collapse and propel fluid forward, with the valvular structure of the lymphatic 
capillaries allowing only unidirectional flow of lymph (Mazzoni et al. 1990).

RBCs constitute about $45 \%$ of blood volume, represents a large sink for accepting plasma ions during exercise. In case of rapidly increasing plasma $\mathrm{H}, \mathrm{K}$ and Lactate ions and osmolality, there is a net movement of solute into RBCs by the ability to regulate cell volume via K-linked transport mechanisms and to regulate $\mathrm{H}$ ions by $\mathrm{Na}$ - and Cl-linked transport mechanisms. This indicates a rapid rate of removal of $\mathrm{K}$ from the plasma compartment (Miller et al., 2005).

In the contracting muscle lactate dehydrogenase (LDH) is abundantly expressed with high activity in the end of glycolysis controlling lactate-to-pyruvate $(\mathrm{La} / \mathrm{P})$ ratio according to oxygenation status. Furthermore, since lactate and pyruvate in plasma, equilibrate with cytosolic concentrations of all cells in the body, these two metabolites provide for redox coupling between organs via blood. During exercise the lactate and pyruvate released from muscles to blood may influence the intracellular $\mathrm{La} / \mathrm{P}$ of the tissue and thereby provide a feedback signal (Cairns 2006).

Lactate and $\mathrm{H}$ ions influence carnitine palmitoyl-transferase 1 (CPT1) function, thereby reducing fat oxidation and prompting a shift towards carbohydrate oxidation becoming the predominant fuel utilized. Availability of $\mathrm{O} 2$ reconverts lactate to pyruvate for oxidative phosphorylation and TCA cycle. Lactate resembles hypoxic conditions, influencing angiogenesis, oxidative defense mechanisms and collagen synthesis, all serving to improve muscle function. (Philp et al., 2005).

Repeated bouts of exercise training achieved by the training program increased lactate reutilization and oxidation to pyruvate with significant decrease in $\mathrm{La} / \mathrm{P}$ ratio. The improved results may lead to higher performance with better energy expenditure and longer time span for fatigue (Jussila and Alitalo 2002 and Hansen et al., 2005).

The key finding of this study is that physical fitness was related to the program, providing general support for the notation that lymph system improvement is associated with physically fit subjects more likely to perform better.
Physical inactivity among youth and its relation to heightened incidences of disease has become a national health concern. Nearly half of young people, ages $12-21$, are not vigorously active on a regular basis (USDHHS, 2000), yet physical activity poses a wealth of benefits to those who participate regularly (e.g., in the areas of adiposity, mental health, musculoskeletal health (Strong et al., 2005). Since physical activity is not synonymous to physical fitness, programmed activity leads to physical fitness (Vanhees et al., 2005).

Exercise is a hyper filtration state, during which the arterial blood pressure and muscle blood flow are markedly increased. These, together with exercise induced Tissue massage, the so called milking action, are considered the prime causes for increased lymph flow during exercise. Skeletal muscles are of interest mainly because during exercise their circulation and metabolism are most dramatically changed, and also because the lymphatic system in skeletal muscle has its own specific characteristics (Havas et al., 2000). With the program adaptation, lymph flow clearance is increased leading to waste wash out with improved performance revealed.

\section{Conclusion}

Regular training program increased lymph function via lymph angiogenesis, lymph flow, redistribution of $\mathrm{La} / \mathrm{P}$ ratio with increased lactate reutilization, increased regulation of waste product clearance via lymph nodules with improved cellular integrity by preserving $\mathrm{Na} / \mathrm{K}$ gradient. Physical performance has developed with better field results achievement.

\section{References}

1. Allen DG, Lamb GD, Westerblad H. Skeletal muscle fatigue: cellular mechanisms. Physiol Rev, 2008; 88: 287-332.

2. Cairns SP. Lactic acid and exercise performance: culprit or friend? Sports Med, 2006; 36: 279-291.

3. Cairns SP, Lindinger MI. Do multiple ionic interactions contribute to skeletal muscle fatigue? J Physiol, 2008; 586 (17): 4039-4054 
4. Castelli DM, Hillman CH, Buck SM, Erwin HE. Physical Fitness and Academic Achievement in Third- and Fifth-Grade Students. Journal of Sport \& Exercise Psychology, 2007; 29: 239-252

5. Clausen T. Na+-K+ pump regulation and skeletal muscle contractility. Physiol Rev, 2003; 83: $1269-1324$.

6. Decherchi P, Darques JL, Jammes Y. Modifications of afferent activities from tibialis anterior muscle in rat by tendon vibrations, increase of interstitial potassium or lactate concentration and electrically-induced fatigue. J Periph Nerv Sys, 1998; 3: 267-276.

7. Haljamae HA, Linde A, Amundson B. Comparative analyses of capsular fluid and interstitial fluid. Am. J. Physiol, 1974; 227: 1199-1205

8. Hansen AK, Clausen T, Nielsen OB. Effects of lactic acid and catecholamines on contractility in fast-twitch muscles exposed to hyperkalemia. Am J Physiol Cell Physiol, 2005; 289: C104-C112.

9. Havas E, Lehtonen M, Vuorela J, Parviainen T, Vihko V. Albumin clearance from human skeletal muscle during prolonged Steadystate running. Experimental Physiology, 2000; 85(6): $863-868$

10. Juel C, Pilegaard H, Nielsen JJ, Bangsbo J. Interstitial $\mathrm{K}$ in human skeletal muscle during and after dynamic graded exercise determined by microdialysis. Am J Physiol Regul Integr Comp Physiol, 2000; 278: R400-R406

11. Jussila L, Alitalo K. Vascular Growth Factors and Lymphangiogenesis. Physiol Rev, 2002; 82: 673-700

12. Karelis AD, Marcil M, P'eronnet $F$, Gardiner PF. Effect of lactate infusion on Mwave characteristics and force in the rat plantaris muscle during repeated stimulation in situ. J Appl Physiol, 2004; 96: 2133-2138.

13. Kristensen M, Albertsen J, Rentsch M, Juel C. Lactate and force production in skeletal muscle. J Physiol, 2005; 562: 521-526.

14. Kristensen M, Hansen T, Juel C. Membrane proteins involved in potassium shifts during muscle activity and fatigue. Am J Physiol Regul Integr Comp Physiol, 2006; 290: R766-R772.
15. Lindinger, JI., McKelvie RS, Heigenhauser JF. K1 and Lac2 distribution in humans during and after high-intensity exercise: role in muscle fatigue attenuation? J Appl Physiol, 1995; 78: 765-777.

16. Mazzoni MC, Skalak TC, SchmidSch GW. Effects of skeletal muscle fibre deformation on lymphatic volumes. American Journal of Physiology, 1990; 259: H1860-1868.

17. McKenna MJ, Bangsbo J, Renaud JM. Muscle $\mathrm{K}, \mathrm{Na}$ and $\mathrm{Cl}$ disturbances and $\mathrm{Na}-\mathrm{K}$ pump inactivation: implications for fatigue. $\mathrm{J}$ Appl Physiol, 2008; 104: 288- 295.

18. Miller F, Lindinger I, Fattor J, Jacobs K, LeBlanc P, Duong M, Heigenhauser G, Brooks G. Hematological and acid-base changes in men during prolonged exercise with and without sodiumlactate infusion. J Appl Physiol, 2005; 98: 856-865

19. Pepper MS, Skobe M. Lymphatic endothelium: morphological, molecular and functional properties. The Journal of Cell Biology, 2003; 163 (2): 209 - 213.

20. Philp A, Adam L, Macdonald AL, Watt PW. Lactate - a signal coordinating cell and systemic function. The Journal of Experimental Biology, 2005; 208: 4561-4575

21. Putman CT, Jones NJ, Heigenhauser GJ. Effects of short-term training on plasma acidbase balance during incremental exercise in man. J Physiol, 2003; 550 (2): 585-603

22. Quick CM, Ngo BL, Venugopal AM, Stewart RH. Lymphatic pump-conduit duality: contraction of postnodal lymphatic vessels inhibits passive flow. Am J Physiol Heart Circ Physiol, 2009; 296: H662-H668.

23. Rasmussen $\mathrm{P}$, Madsen CA, Nielsen HB, Zaar M, Gjedde A, Secher NH, Quistorff B. Coupling between the blood lactate-topyruvate ratio and MCA Vmean at the onset of exercise in humans. J Appl Physiol, 2009; 107: 17991805

24. Schmid-Schonbein GW. Microlymphatics and lymph flow. Physiol Rev, 1990; 70: 9871028

25. Skalak TC, SchmidSch GW, Zweifach BW. New morphological evidence for a mechanism 
of lymph formation in skeletal muscle. Understanding and improving health. Microvascular Research, 1984; 28: 95 -112. Washington, DC: U.S. Government Printing 26. Strong WB, Malina RM, Blimkie CJ, Office, 2010; 22B: 1-25.

Daniels SR, Dishman RK, Gutin B, et al. 28. Vanhees L, Lefever J, Philippearets R, Evidence based physical activity for school-age Matrens M, Huygens W, Troosters T, Beunen youth. Journal of Pediatrics, 2005; 146: 732- G. How to assess physical activity? How to 737

27. U.S. Department of Health and Human Services (USDHHS). Healthy people 2010: assess physical fitness? European journal of cardiovascular prevention and rehabilitation, 2005; $12: 102-114$. 